\title{
EVALUASI BIAYA OPERASIONAL ANGKUTAN UMUM DI KOTA PALOPO
}

\author{
Rakhmawati Natsir ${ }^{1)}$ \\ ${ }^{1)}$ Dosen Program Studi Teknik Sipil, Universitas Andi Djemma, Palopo \\ 1) wathi07@gmail.com
}

\begin{abstract}
Abstrak
Angkutan umum sebagai bagian dari sistem transportasi perkotaan adalah salah satu kebutuhan pokok masyarakat kota dan merupakan bagian yang tidak dapat dipisahkan dari kehidupan kota pada umumnya. Biaya operasional yang merupakan salah satu dasar dalam penetapan tarif. Penelitian ini dilakukan pada angkutan umum di kota Palopo untuk trayek terminal - perumnas. Desain penelitian secara kuantitatif dengan melakukan pengambilan data primer dan data sekunder untuk mengetahui faktor-faktor yang mempengaruhi biaya operasional angkutan umum. Data yang diperoleh diolah dengan menggunakan model rumus matematis untuk mencari besarnya biaya operasional kendaraan (BOK) angkutan umum pada trayek terminal - perumnas. Berdasarkan hasil perhitungan biaya operasi kendaraan (BOK) dan tambahan biaya lainnya yang ditunjukkan pada trayek terminal-perumnas, bahwa biaya yang harus dikeluarkan perkendaraan (mikrolet/pete-pete) per tahunnya sebesar $=\mathrm{Rp}$ $100.492 .828,15$ dengan biaya perkilometernya sebesar $=1.595 .12 \mathrm{~km} / \mathrm{thn}$.
\end{abstract}

Kata Kunci: Angkutan Umum, BOK, Sistem Informasi

\section{PENDAHULUAN}

Angkutan umum sebagai bagian dari sistim transportasi perkotaan adalah salah satu kebutuhan pokok masyarakat kota dan merupakan bagian yang tidak dapat dipisahkan dari kehidupan kota pada umumnya.keberadaan angkutan kota sangat dibutuhkan tetapi apabila tidak ditangani secara baik dan benar merupakan masalah bagi kota. Tingkat pertumbuhan yang sangat tinggi yang tidak mungkin di hambat sementara sarana dan prasana transportasi sangat terbatas mengakibatkan aksesibilitas dan mobilitas terganggu.sekarang ini program pembangunan jalan didaerah perkotaan membutuhkan biaya yang sangat besar. Usaha pemerintah untuk memecahkan masalah trasportasi perkotaan telah banyak dilakukan baik dengan meningkatkan kapasitas jaringan jalan yang ada maupun dengan pembangunan jaringan jalan yang baru ditambah dengan rekayasa dan manajemen lalu lintas terutama pengaturan efisiensi transportasi angkutan umum.

Seiring dengan pertumbuhan permintaan pelayanan transportasi untuk mendukung kegiatan masyarakat yang berkembang dengan sangat cepat jumlah kendaraan di kota palopo dari waktu ke waktu terus bertambah tetapi pertumbuhan tersebut tidak diimbangi dengan pertambahan panjang dan kapasitas jalan. Jalan menjadi sangat padat kecepatan perjalanan menurun dan kenyamanan berlalu lintas menurun dan kemacetan secara potensial menjadi ancaman hampir diseluruh jaringan jalan dalam kota.

Pertumbuhan penduduk dari tahun ke tahun semakin meningkat,sehingga jumlah pemakai prasarana jalan semakin meningkat pula akibatnya volume lalulintas bertambah besar sehingga menyebabkan kurang berfungsinya angkutan umum secara optimal yang mengakibatkan kemacetan lalu lintas sehingga terjadi antrian panjang, tundaan dan juga polusi baik itu suara maupun udara, hal ini jelas menimbulkan kerugian yang sangat besar pada pemakai jalan terutama dalam hal ini pemborosan bahan bakar, pemborosan waktu (tundaan) dan juga rendahnya kenyamanan. Meningkatnya jumlah armada yang beroperasi pada rute terminal antara wilayah dalam kota Palopo kurangnya keseriusan dinas perhubungan kota palopo untuk 
mengatur dan mengeluarkan kebijakan terhadap kendaraan yang dapat beroprasi menyebabkan jumlah armada yang beroperasi bertambah pada rute tersebut. Jumlah angkutan umum (mikrolet/pete-pete) yang semakin banyak pada salah satu rute yang mengakibatkan selain load faktor kendaraan menurun juga terjadi proses buching. atau saling menempel kendaraan sehingga terjadinya perebutan penumpang dan gangguan pada lalu lintas yang menyebabkan kinerja prasarana jalan semakin berkurang sehingga mengakibatkan biaya operasional angkutan meningkat.

Berdasarkan uraian di atas maka dilakukan penelitian yang bertujuan untuk mengevaluasi biaya operasional angkutan umum kota Palopo khususnya trayek teminal-perumnas.

\section{METODOLOGI PENELITIAN}

Penelitian ini dilakukan pada angkutan umum di kota Palopo untuk trayek terminal - perumnas. Desain penelitian secara kuantitatif dengan melakukan pengambilan data primer dan data sekunder untuk mengetahui faktor-faktor yang mempengaruhi biaya operasional angkutan umum. Tahapan awal dari penelitian ini adalah mengumpulkan data sekunder dan data primer. Data sekunder yang digunakan diperoleh pada instansi-instansi terkait antara lain sistem tarif yang berlaku dan besaran tarif jumlah kendaraan yang beroperasi pada trayek terminal-perumnas. Pengambilan data primer dengan melakukan wawancara kepada sopir angkutan umum untuk mendapatkan informasi terkait biaya dan pemakaian bahan bakar, ban, biaya retribusi, pelumas, pemeliharaan kendaraan serta upah. Pada penelitian ini data yang diperoleh diolah dengan menggunakan model rumus matematis untuk mencari besarnya biaya operasional kendaraan (BOK) angkutan umum pada trayek terminal perumnas.

\section{HASIL DAN PEMBAHASAN}

Angkutan umum yang ada di Kota Palopo sangat dipengaruhi jumlah trayek yang ada. Pembagian jumlah trayek didasarkan atas banyaknya pengguna jasa kendaraan umum angkutan kota yang menempati suatu daerah. Dengan adanya pembagian trayek ini menghasilkan keteraturan jurusan/rute yang dilalui oleh masing-masing angkutan umum kota. Dengan trayek yang sudah ditentukan, juga akan memudahkan bagi pengguna jasa angkutan umum mengetahui daerah mana yang akan dituju yang akan dilalui oleh angkutan umum.

Jumlah trayek yang ada diwilayah kota palopo sebanyak Tujuh Trayek. Adapun trayek yang dimaksud adalah sebagi berikut:

1) Trayek I : Terminal - Perumnas - Rampoang - Pepabri

2) Trayek II : Terminal - Latuppa-Sendana

3) Trayek III : Terminal - Binturu - Songka

4) Trayek IV : Terminal - Jembatan Miring

5) Trayek V : Terminal - Nyiur - Hartaco

6) Trayek VI : Terminal - Lebang

7) Trayek VII : Terminal - Pelabuhan Tanjung Ringgit

Tapi jumlah Trayek yang beroprasi sekarang ini ada dua Trayek yaitu:

1) Trayek I : Terminal - Perumnas - Rampoang - Pepabri

2) Trayek III : Terminal - Binturu - Songka

Berdasarkan hasil perhitungan biaya tetap, biaya tidak tetap dan pendapatan kendaraan per tahunnya, antara lain : 
a) Biaya operasional angkutan umum merupakan penjumlahan dari biaya tetap dan biaya-biaya tidak tetap dan untuk mendapatkan besaran biaya operasi angkutan umum sesuai dengan tarif yang berlaku.

b) Hasil perhitungan kendaraan pertahunnya berdasarkan hari operasi kendaraan memperlihatkan bahwa pendapatan yang diperoleh masih dapat menutupi biaya operasional kendaraan yang di operasikan.

Berdasarkan hasil perhitungan biaya operasi kendaraan (BOK) dan tambahan biaya lainnya yang ditunjukkan pada trayek terminal-perumnas, bahwa biaya yang harus dikeluarkan perkendaraan (mikrolet/pete-pete) per tahunnya sebesar $=\mathrm{Rp}$ $100.492 .828,15$ dengan biaya perkilometernya sebesar $=1.595 .12 \mathrm{~km} / \mathrm{thn}$.

Dalam melakukan evaluasi biaya operasional kendaraan angkutan umum dilakukan secara full cost, dengan menghitung biaya tetap dengan biaya tidak tetap berdasarkan tarif yang berlaku.

\section{Perhitungan BOK}

1) Karakteristik kendaraan

$\begin{array}{ll}\text { Jenis kendaraan } & \text { : Suzuki carry }(2005) \\ \text { Harga kendaraan } & \text { : Rp. } 120.000 .000,00 \\ \text { Kapasitas angkut } & \text { : } 10 \text { tempat duduk }\end{array}$

2) Produksi angkutan per unit
Panjang trayek (PT)
$: 7 \mathrm{~km}$
Frekuensi (F)
$: 5 \mathrm{rit} / \mathrm{hari} \times 2=10(\mathrm{pp})$
Hari operasi perbulan (HOB) : 30 hari
Km. Tempuh per hari $(\mathrm{KTH}) \quad:(\mathrm{PT}) \times \mathrm{F}$
$: 7 \times 10=70$
$\mathrm{Km}$. Tempuh per bulan (KTB) : (KTH) x (HOB)
$: 70 \times 30=2100 \mathrm{~km}$
Km. Tempuh per tahun (KTT) : (KTB) $x 12$ bulan
: $2100 \times 12=25200 \mathrm{~km}$
Hari operasi per tahun (HOT) : (HOB) x 12 bulan
: $30 \times 12=360$ hari

3) Perhitungan Biaya Tetap (fixed cost) meliputi :

a) Biaya Penyusutan

Nilai penyusutan dengan garis lurus

1. Harga awal (P) : Rp. 120.000.000,00

2. Umur ekonomis (n) $: 5$ tahun

3. Nilai residu (NR) : $20 \% \mathrm{x}$ harga awal

4. Harga sisa : Rp. 24.000.000,00

Jadi biaya penyusutan pertahun adalah :

$\mathrm{D}=\frac{\text { harga awal }(\mathrm{P})-\text { harga sisa }(\mathrm{L})}{\text { umur ekonomis }(\mathrm{n})}=\mathrm{Rp} /$ tahun

$\mathrm{D}=\frac{\mathrm{Rp} .120 .000 .000-\mathrm{Rp} .24 .000 .000}{5}=\mathrm{Rp} .19 .200 .000,00 /$ Tahun

Jadi biaya penyusutan per kilometer adalah :

$\mathrm{D} / \mathrm{Km}=\frac{\operatorname{Harga} \operatorname{Kendaraan}(\mathrm{P})-\operatorname{Harga} \text { sisa }(\mathrm{L})}{\operatorname{KTT} \times \operatorname{Umur} \text { Ekonomis }(\mathrm{n})}$

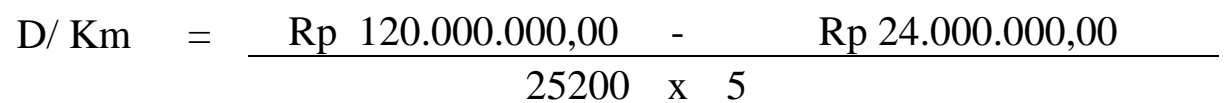




$$
\begin{aligned}
& =\frac{\operatorname{Rp} 96.000 .000,00}{126000} \\
& =\operatorname{Rp} 761,90 \quad \mathrm{rm}
\end{aligned}
$$

b) Biaya Bunga Modal

Biaya bunga modal dihitung dengan rumus :

- Harga kendaraan = Rp. 120.000.000,-

- Suku bunga $\quad=16 \%$ per tahun

- Jangka waktu pinjaman $=5$ tahun

Maka $\mathrm{BM}=\{(5+1) / 2 \times(120.000 .000 \times 16 \%) / 5\}+(120.000 .000 / 5)$

$$
\mathrm{BM}=\mathrm{Rp} .35 .520 .000,-
$$

Biaya bunga modal per bulan per angkot adalah :

$$
\begin{array}{rlr}
\mathrm{BM} & =\frac{\operatorname{Rp} 35.520 .000,00}{12} \\
& =\quad \operatorname{Rp} 2.960 .000
\end{array}
$$

Sehingga didapat biaya per kilometer yaitu :

$$
\mathrm{BM}=\frac{\mathrm{Rp} 2.960 .000}{25200}
$$

c) Biaya Kru

$$
=\quad \text { Rp. } 117 / \mathrm{km}
$$

Sesuai dengan sistem yang berjalan pada pengoperasian angkutan kota di palopo. Dimana kru digaji berdasarkan hari operasinya maka biaya kru termaksud biaya variabel. Dari hasil survey wawancara diperoleh bahwa ratarata biaya kru adalah : Gaji kru $=$ Rp. 70.000,- / hari Sehingga total biaya $=$ Rp. 70.000,- x $360=$ Rp. 25.200.000,-/thn Sehingga biaya $\mathrm{km}$ per tahun adalah

$$
\frac{25.200 .000,00}{25200}=\operatorname{Rp} 1.000,00 / \mathrm{km}
$$

d) Biaya Retribusi

Biaya retribusi adalah biaya sekali bayar dalam sehari pada pos atau terminal pada saat mobil sedang dioperasikan.

Biaya retribusi per angkot $=\mathrm{Rp} .1 .000,-$

Hari operasi per tahun $=360 /$ hari

Jadi biaya retribusi per tahun adalah $\mathrm{Br}=\mathrm{Rp} .1 .000 \times 360=\mathrm{Rp} .360 .000$,/thn

Sehingga biaya per kilometer adalah :

$$
\begin{array}{cc}
\begin{array}{c}
\mathrm{Rp} \\
360.000,00
\end{array} & \mathrm{Rp} 14,29 \\
25200 & / \mathrm{km}
\end{array}
$$

e) Biaya pajak kendaraan

Biaya pajak $(\mathrm{L}) \quad=5 \%$ dari harga kendaraan

Harga kendaraan = Rp. 120.000.000,- 
Per tahun kendaraan :

$$
\begin{aligned}
& =5 \% \times \text { Rp. } 120.000 .000,- \\
& =\text { Rp. } 6.000 .000,-
\end{aligned}
$$

Jadi biaya per kilometer per tahun adalah

$$
\begin{aligned}
& \text { Per } \\
& \text { kilometer } \\
& =\frac{\text { per tahun kendaraan }}{\text { KTT }} \\
& \text { Per kilometer }=\frac{\mathrm{Rp} 6.000 .000,00}{25200}=\begin{array}{c}
\mathrm{Rp} \mathrm{238,10} \\
/ \mathrm{Km}
\end{array}
\end{aligned}
$$

Dari hasil perhitungan biaya operasional tetap pada kendaraan maka total biaya operasi biaya total sebesar Rp. 2.131,75.

4) Perhitungan biaya tidak tetap (Runing cost) meliputi :

a) Biaya bahan bakar

Konsumsi bahan bakar dapat dihitung dengan rumus 3.7 :

Faktor koreksi akibat kelandaian (Kk)

$$
\begin{aligned}
& =-0,158(-5<\mathrm{g}<0 \%) \\
& =0,253(\mathrm{NVK} \geq 0,8) \\
& =0,035(\mathrm{IRI}<3 \mathrm{~m} / \mathrm{km}) \\
& =(1-0,158+0,253+0,035) \\
& =1,130
\end{aligned}
$$$$
\text { Faktor koreksi akibat kekasaran jalan }(\mathrm{Kr})
$$

Konsumsi bahan bahar menurut kecepatan rata-rata pada trayek terminal perumnas maka dapat dihitung konsumsi bahan bakar pada tabel berikut:

Tabel 1. Konsumsi bahan bakar

\begin{tabular}{c|c|c|c|c|c|c}
\hline $\begin{array}{c}\text { Kecepatan } \\
(\mathrm{km} / \mathrm{jam})\end{array}$ & $\begin{array}{c}\text { Panjang } \\
\text { Perjalanan } \\
(\mathrm{km} / \mathrm{jam})\end{array}$ & $\begin{array}{c}\text { KKB } \\
\text { Dasar }\end{array}$ & $\begin{array}{c}\mathrm{KKB} \\
(\mathrm{liter} / 1000 \\
\mathrm{km})\end{array}$ & $\begin{array}{c}\mathrm{KBB} \\
(\mathrm{liter} / \mathrm{thn})\end{array}$ & $\begin{array}{c}\mathrm{KBB} \\
(\mathrm{Rp} / \mathrm{thn})\end{array}$ & $\begin{array}{c}\text { KBB } \\
(\mathrm{Rp} . / \mathrm{Km})\end{array}$ \\
\hline$(\mathrm{B})$ & $(\mathrm{C})$ & $(\mathrm{D})$ & $(\mathrm{E}=\mathrm{DxK})$ & $\begin{array}{c}\mathrm{f}=\mathrm{ExC} / 1000 \\
/ 360)\end{array}$ & $\begin{array}{c}(\mathrm{G}=\mathrm{F} \\
\mathrm{X} 6500)\end{array}$ & $\begin{array}{c}\mathrm{H}= \\
(\mathrm{G} / \mathrm{KTT})\end{array}$ \\
\hline 30 & 50 & 75,308 & 85,0980 & $2.144,471$ & 13.939 .059 & 553,14 \\
\hline
\end{tabular}

Sumber Hasil Analisis

b) Biaya minyak pelumas

Konsumsi dasar minyak pelumas sesuai dengan kecepatan rata-rata kendaraan dapat dilihat pada tabel, dan faktor koreksi untuk IRI pada tabel 2,sehingga biaya minyak pelumas di hitung seperti tabel 2 berikut :

Tabel 2. Konsumsi minyak pelumas

\begin{tabular}{c|c|c|c|c|c|c}
\hline $\begin{array}{c}\text { Kecepata } \\
\mathrm{n} \\
(\mathrm{Km} / \mathrm{Jam})\end{array}$ & $\begin{array}{c}\text { Panjang } \\
\text { Perjalanan } \\
(\mathrm{Km} / \mathrm{Jam})\end{array}$ & $\begin{array}{c}\text { Konsumsi } \\
\text { Dasar } \\
(\mathrm{ltr} / \mathrm{Km})\end{array}$ & $\begin{array}{c}\text { Faktor } \\
\text { Koreksi } \\
\text { Untuk IRI }\end{array}$ & $\begin{array}{c}\text { Konsums } \\
\text { i Minyak } \\
\text { Pelumas } \\
(\mathrm{Ltr} / \mathrm{Thn})\end{array}$ & $\begin{array}{c}\text { Konsumsi } \\
\text { Minyak } \\
\text { Pelumas } \\
(\mathrm{Rp} / \mathrm{thn})\end{array}$ & $\begin{array}{c}\text { Konsumsi } \\
\text { Minyak } \\
\text { Pelumas } \\
(\mathrm{Rp} / \mathrm{Km})\end{array}$ \\
\hline$(\mathrm{B})$ & $(\mathrm{C})$ & $\begin{array}{c}\mathrm{D})=\text { tabel } \\
3\end{array}$ & $\begin{array}{c}\mathrm{E}=\text { tabel } \\
4)\end{array}$ & $\begin{array}{c}(\mathrm{F}=\mathrm{C} \times \\
\mathrm{D} \times 360)\end{array}$ & $\begin{array}{c}(\mathrm{G}=\mathrm{F} \times \\
35000)\end{array}$ & $\begin{array}{c}(\mathrm{H}= \\
\mathrm{G} / \mathrm{KTT})\end{array}$ \\
\hline 30 & 70 & 0,003 & 1,000 & 70,560 & $\begin{array}{c}2.469 .600,0 \\
00\end{array}$ & 98,0 \\
\hline
\end{tabular}

Sumber Hasil Analisis

c) Biaya ban

Biaya ban dihitung perhitungan dapat dilihat pada tabel berikut :

Tabel 3. Biaya pemakaian ban

\begin{tabular}{c|c|c|c|c|c|c}
\hline $\begin{array}{c}\text { Kecepatan } \\
(\mathrm{Km} / \mathrm{Jam})\end{array}$ & $\begin{array}{c}\text { Panjang } \\
\text { Perjalanan }\end{array}$ & $\begin{array}{c}\text { Biaya } \\
\text { Ban }\end{array}$ & $\begin{array}{c}\text { Pemakaian } \\
(\mathrm{bh} /\end{array}$ & $\begin{array}{c}\text { Pemakaian } \\
(\mathrm{bh} /\end{array}$ & $\begin{array}{c}\text { Pemakaian } \\
\text { Ban }\end{array}$ & $\begin{array}{c}\text { Pemakaian } \\
\text { Ban }\end{array}$ \\
\hline
\end{tabular}




\begin{tabular}{c|c|c|c|c|c|c}
\hline & $(\mathrm{Km} / \mathrm{Jam})$ & $(\mathrm{bh} / \mathrm{jam})$ & $\begin{array}{c}\text { kendaraan/ } \\
1000 \mathrm{~km})\end{array}$ & $\begin{array}{c}\text { kendaraan/ } \\
1000 \mathrm{~km})\end{array}$ & $(\mathrm{Rp} / \mathrm{thn})$ & $(\mathrm{Rp} / \mathrm{Km})$ \\
\hline & & & $\begin{array}{l}(\mathrm{F}=\mathrm{E} \times \\
\mathrm{C} / 1000 * 360 \\
)\end{array}$ & $(\mathrm{D})$ & $\begin{array}{c}(\mathrm{G}=\mathrm{F} \times \\
300000)\end{array}$ & $\begin{array}{c}(\mathrm{H}= \\
\mathrm{G} / \mathrm{KTT})\end{array}$ \\
\hline 30 & 70 & 0,02201 & 0,088 & 2.219 & 665.604 & 26,4128 \\
\hline
\end{tabular}

Sumber Hasil Analisis

d) Biaya perawatan

Biaya perawatn terdiri dari perbaikan, penggantian suku cadang, pembentukan komponen mekanik dan tenaga dihitung sebagai berikut :

Umur ekonomis kendaraan adalah 5 tahun, maka jumlah digit tahun adalah 15 $(1+2+3+4+5)$, Maka biaya perawatan adalah :

Tahun $1=1 / 15$ x $40 \%$ x Rp. $120.000 .000,-=$ Rp. $3 \cdot 200.000,00$

Tahun II $=2 / 15 \times 40 \%$ x Rp. 120.000.000,- = Rp. 6.400.000,00

Tahun III $=3 / 15$ x $40 \%$ x Rp. $120.000 .000,-=$ Rp. $9.600 .000,00$

Tahun VI $=4 / 15$ x $40 \%$ x Rp.120.000.000,- = Rp. 12.800.000,00

Tahun V $=5 / 15 \times 40 \%$ x RP.120.000.000,- = RP. 16.000.000,00

Jadi total biaya perawatan adalah $=$ RP.48.000.000,00 atau rata-rata Rp.9.600.000,00 per tahun

Jadi total biaya pemeliharaan $=\underline{\text { Rp. } 9 \cdot 600.000,00}$

$$
25200
$$$$
=\mathrm{Rp} \cdot 380,95 \mathrm{Km}
$$

Dari hasil perhitungan biaya operasi tidak tetap pada kendaraan, maka total biaya operasi tidak tetap sebesar $=$ Rp.1.058.50 Km

e) Biaya operasional kendaraan

Biaya operasional kendaraan (BOK) merupakan penjumlahan dari biaya tetap dan biaya-biaya tidak tetap dan untuk mendapatkan besaran biaya operasi kendaraan yang sesuai dengan tarif yang berlaku maka biaya BOK perlu ditambah dengan biaya-biaya lainnya yaitu biaya overhead, biaya tak terduga,dan keuntungan pemilik. Perincian biaya operasional kendaraan dan BOK dengan penambahan biaya-biaya lain, yaitu biaya tak terduga diambil 5\% dari BOK. Biaya overhead yang merupakan biaya pengelolah atau pegawai administrasi diasumsikan sama dengan nol.

Tabel 4. Biaya operasional kendaraan dan tambahan biaya lainnya

\begin{tabular}{|c|c|c|c|c|c|c|c|}
\hline $\begin{array}{c}\text { Biaya } \\
\text { Tetap } \\
\text { (Rp./Thn) }\end{array}$ & $\begin{array}{c}\text { Biaya } \\
\text { Tidak } \\
\text { Tetap } \\
\text { (Rp./Thn) }\end{array}$ & $\begin{array}{c}\text { BOK } \\
\text { (Rp./Th } \\
\text { n) }\end{array}$ & $\begin{array}{l}\text { Over } \\
\text { head }\end{array}$ & $\begin{array}{c}\text { Biaya Tak } \\
\text { Terduga 5\% x } \\
\text { BOK } \\
\text { (Rp./Thn) }\end{array}$ & $\begin{array}{c}\text { Keuntungan } \\
20 \% \text { x BOK } \\
\text { (Rp./Thn) }\end{array}$ & $\begin{array}{l}\text { Total Biaya - } \\
\text { BOK + lain } \\
2 \text { (Rp./Thn) }\end{array}$ & $\begin{array}{c}\text { Total } \\
\text { Biaya }= \\
\text { BOK }+ \\
\text { lain } 2 \\
(\mathrm{Rp} / \mathrm{Km})\end{array}$ \\
\hline (B) & (C) & $\begin{array}{c}(\mathrm{D}=\mathrm{B} \\
+\mathrm{C})\end{array}$ & (E) & $(\mathrm{F}=5 \% \times \mathrm{D})$ & $(\mathrm{G}=20 \% \times \mathrm{D})$ & $\begin{array}{c}(\mathrm{H}= \\
\mathrm{D}+\mathrm{E}+\mathrm{F}+\mathrm{G})\end{array}$ & $\begin{array}{c}(\mathrm{I}=(\mathrm{BT}+ \\
\mathrm{BTT}) / 2)\end{array}$ \\
\hline 53.720 .000 & 26.674 .263 & $\begin{array}{l}80.394 . \\
263\end{array}$ & - & 4.019 .731 & 16.078 .853 & 100.492 .828 & 1.595 \\
\hline
\end{tabular}

\section{Sumber Hasil Analisis}

Berdasarkan hasil perhitungan biaya operasi kendaraan (BOK) dan tambahan biaya lainnya yang ditujukan pada tabel 3, pada trayek terminal-perumnas bahwa biaya yang harus dikeluarkan perkendaraan (mikrolet/pete-pete) pertahunnya sebesar $=$ Rp.100.492.828,15 dengan biaya perkilometer sebesar Rp. 1.595 .12 $\mathrm{km} / \mathrm{thn}$. 


\section{Perhitungan (BOK) berdasarkan Tarif}

Biaya operasi yang dihitung berdasarkan tarif adalah untuk mengetahui seberapa besar biaya yang harus dikeluarkan untuk menutupi biaya pengoperasian kendaraan tersebut selama beroperasi dan pendapatan sisa yang dapat dari biaya yang dikeluarkan atau keuntungan yang diperoleh. Untuk lebih jelasnya lihat.

Berdasarkan hasil perhitungan biaya operasional kendaraan tarif angkutan pada trayek terminal-perumnas ,tarif yang diperoleh lebih kecil dari tarif yang berlaku dilapangan. Dengan hasil tersebut angkutan kota yang beroperasi masih mampu menutupi biaya biaya operasional kendaraannya dan tetap memperoleh keuntungan, hal ini disebabkan masih ada selisih dari perhitungan BOK dengan tarif yang berlaku di lapangan yang di tetapkan rata-rata 300-650 Rupiah/km

\section{KESIMPULAN}

Berdasarkan hasil dan pembahasan di atas, maka dapat diperoleh kesimpulan sebagai berikut:

1) Berdasarkan jumlah penumpang umum ( mikrolet) yang beroperasi pada trayek angkutan local Kota Palopo adalah 104 angkutan

2) Berdasarkan hasil perhitungan biaya tetap, biaya tidak tetap dan pendapatan kendaraan per tahunnya, antara lain :

a) Biaya operasional angkutan umum merupakan penjumlahan dari biaya tetap dan biaya-biaya tidak tetap dan untuk mendapatkan besaran biaya operasi angkutan umum sesuai dengan tarif yang berlaku.

b) Hasil perhitungan kendaraan pertahunnya berdasarkan hari operasi kendaraan memperlihatkan bahwa pendapatan yang diperoleh masih dapat menutupi biaya operasional kendaraan yang di operasikan.

3) Berdasarkan hasil perhitungan biaya operasi kendaraan (BOK) dan tambahan biaya lainnya yang ditunjukkan pada trayek terminal-perumnas, bahwa biaya yang harus dikeluarkan perkendaraan (mikrolet/pete-pete) per tahunnya sebesar = Rp 100.492.828,15 dengan biaya perkilometernya sebesar $=1.595 .12 \mathrm{~km} / \mathrm{thn}$.

4) Dari pengamatan langsung di lapangan maka terlihat beberapa hal yang perlu pembenahan dari pihak yang berwenang sebagai berikut:

a) Untuk meminimalkan biaya angkutan umum, maka jumlah mikrolet/pete-pete yang beroperasi pada trayek ini harus dikurangi.

b) Membatasi jumlah angkutan umum yang beroperasi, Hal ini disebabkan untuk mengurangi terjadinya kesembrawutan, kepadatan, dan kemacetan lalu lintas khususnya pada trayek terminal-perumnas agar dapat dioptimalkan.

c) Pembatasan dan efisiensi jumlah angkutan umum (mikrolet/pete-pete) agar kelangsungan pengusaha angkutan umum dapat terjamin.

\section{DAFTAR PUSTAKA}

Abu Bakar, Ir., MSc, Judiza. R. Z., Ir., MSc., dkk. 1997. Menuju Lalu Lintasdan Angkutan Jalan Yang Tertib, Jakarta: Direktorat Jendral Perhubungan Darat.

Adisasmita, R. 2010. Dasar-dasar Ekonomi Transportasi. Graha Ilmu. Yogyakarta.

Amiruddin Basir, H., Ir., Syarifuddin Rauf, Ir. 1998. Bahan Kuliah Terminaldan Perparkiran. Makassar.

Anonymous. 2005. Kota Palopo Dalam Angka Tahun 2005. Palopo: BPS Kota Palopo. 
Anonymous. 1997. Himpunan Keputusan Menteri Perhubungan Sebagai Pelaksanaan UU No. 14/1992 Tentang Lalu Lintas Dan Angkutan Jalan( Buku III). Jakarta: Direktorat Jendral Perhubungan Darat.

Giatman, M. 2006. Ekonomi Teknik. Jakarta:Raja Grafindo Persada.

Hobbs, F. D.. 1995. Perencanaan dan Teknik Lalu Lintas. Yogyakarta: Gajah Mada University Press.

Kamaluddin R. 2003. Ekonomi Tranportasi. Jakarta: Ghalia Indonesia.

Miro F. 2005. Perencanaan Tranportasi. Jakarta: Erlangga

Morlock, Edward K., Hainin, Johan K. 1991. Pengantar Teknik dan Perencanaan Transportasi, Alih bahasa Ir. Johan Kelanaputra Hainim. Jakarta: Erlangga

Oglesby, Clarkson H. dan Hicks, R. Gary. 1988. Pengantar Teknik JalanRaya, Alih bahasa Ir. Purwo Setianto, Edisi ke-4 Jilid 1. Jakarta: Erlangga

Salim, Abbas. 2008. Manajemen Tranportasi. Rajawali Pers

Santoso G. 2005. Metodologi Penelitian (Kuantitatif dan Kualitatif). Jakarta: Prestasi Pustaka Publisher

Well, G.R. 1988. Rekayasa Lalu Lintas. Jakarta: Bharatara

Yamin, Jinca. 2007. Dasar-Dasar Transportasi. Makassar: Universitas Hasanuddin Press 
PENA TEKNIK: Jurnal Ilmiah Ilmu-Ilmu Teknik

Volume 3, Nomor 1, Maret $2016: 47$ - 56

\section{Halaman ini sengaja dikosongkan}

